\title{
ASPECTOS PUNTUALES DE LA \\ LEY 4/1992 DE 5 DE JUNIO, \\ SOBRE SUELO NO URBANIZABLE DE LA \\ COMUNIDAD AUTÓNOMA VALENCIANA, \\ CON INCIDENCIA PARA LA \\ PREVENCIÓN DE RIESGOS NATURALES.
}

\author{
JOSEP OCHOA MONZÓ \\ Becario de Investigación \\ Area de Dret Administratiu
}

\section{Planteamiento}

La Ley 4/1992, de 5 de junio, sobre suelo no urbanizable de la Comunidad Autónoma Valenciana ${ }^{1}$ constituye un hito relevante dentro de nuestro ordenamiento urbanístico, cuya importancia deriva básicamente de dos órdenes distintos de cuestiones. Por una parte, lo que no será objeto de nuestra atención, la Ley determina de forma bastante precisa el nuevo régimen urbanístico del suelo no urbanizable, incorporando novedades ciertamente destacables por lo que a la normación de dicha clase de suelo se refiere ${ }^{2}$. La oportunidad de la reforma legal en este campo viene ya destacada en el Preámbulo de la Ley, de forma rigurosa. El legislador pone su principal punto de atención, en general, en las peculiaridades propias del régimen urbanístico de la Comunidad Valenciana y, en particular, en intentar dar respuesta a los acuciantes problemas a los que desde siempre se ha visto sujeto el planteamiento, en nuestro ámbito territorial, en relación al suelo no urbanizable. Por otra parte, cuestión esta sí sobre la que gravitará nuestra reflexión, la Ley valenciana, siquiera sea tangencialmente, intenta conjugar las necesidades imperiosas de un planteamiento territorial adecuado a la par que introduce determinadas medidas con in-

${ }^{1}$ Diari Oficial de la Generalitat Valenciana, num 1806 de 17 de junio de 1992.

${ }^{2}$ Así por ejemplo, la Ley parte de un concepto positivo del suelo no urbanizable (art. 1 en relación con el punto III del Prámbulo); clasifica primariamente dicho suelo en no urbanizable común (art. 1.3. B) y no urbanizable sujeto a especial protección (art. 1.3. A); introduce una institución de nuevo cuño: la declaración de interés comunitario, como presupuesto para permitir aquellas actuaciones productivas o terciarias que se pretendan acometer en el espacio rústico y que, por su mayor tamaño y trascendencia, alcanzan a ser, en sí mismas, elementos influyentes en la estructura territorial (punto IV apartado $10 \mathrm{del}$ Préambulo). 
cidencias para la prevención de riesgos ${ }^{3}$, ambientales o no, naturales o antrópicos, a cuyo objeto apuntan meridianamente determinados preceptos de la normativa, y cuyo ámbito subjetivo despliega sus efectos tanto para los particulares propietarios de suelo no urbanizable 4 como para las propias Administraciones Públicas.

El objeto por tanto de este trabajo, consistirá precisamente en detectar cuáles son esas medidas que en la Ley valenciana parecen dispuestas para incidir en una mejor gestión de los riesgos naturales a los que se ve expuesto el territorio valenciano. Riesgos que si bien en la Ley se mencionan unas veces de forma genérica ${ }^{5}$ y otras de manera específica ${ }^{6}$, tienen prácticamente todos como punto de referencia, habida cuenta del ámbito material de la misma, la protección del suelo?

\section{Los riesgos naturales ${ }^{8}$}

\subsection{Vertientes del problema.}

La preocupación creciente de la comunidad internacional, particularmentre intensa a partir de la década de los ochenta ${ }^{9}$, por fomentar el desarrollo de medidas de prevención adecuadas que posibiliten una minimización de los riesgos naturales a fin de reducir los cuantiosos daños, tanto materiales, personales como ambientales que llevan aparejados, está calando en la conciencia de los poderes públicos de nuestro país, en las distintas vertientes en que los mismos se manifiestan.

${ }^{3} \mathrm{~A}$ los efectos de esta reflexión consideramos el riesgo como «la posibilidad, proximidad o probabilidad de que ocurra un daño a un elemento considerado», en este caso el suelo.

${ }^{4}$ Incluyendo tanto lo que, en terminología de la Ley, se denomina suelo no urbanizable común (art. 5), como para el suelo no urbanizable sujeto a especial protección (art. 6). En cuanto a que hay que entender por cada una de estas categorías de suelo, hay que estar, en principio, a lo previsto en el art. 1.3. A) por lo que respecta al suelo no urbanizable sujeto a especial protección; y al art. 1.3. B) en cuanto al suelo no urbanizable, en su categoría común.

${ }^{5}$ Así, el art. 5 B) $3^{\circ}$ habla de: «...prevenir desastres naturales».

${ }^{6}$ El art. 5. B) 2o, en cambio, menciona como deberes del propietario de suelo no urbanizable: «...evitar riesgos de erosión, incendio... o cualquier otra perturbación medioambiental...».

${ }^{7} \mathrm{Si}$ bien es cierto que el art. 5. B) 4, obliga tanto al propietario de suelo no urbanizable común, así como el art. 6.2. al propietario de suelo no urbanizable sujeto a especial protección a «abstenerse de realizar cualesquiera actividades o actos que puedan tener como consecuencia o efecto la contaminación de la tierra, el agua o el aire», ampliando con ello la protección a otros elementos ambientales.

${ }^{8}$ Entendidos como «aquellos que obedecen a causas estrictamente naturales» sin participación humana alguna. Dentro de esa categoría se encuentran, entre otros, las inundaciones, los terremotos, las erupciones volcánicas, los vendavales, etc.

${ }^{9}$ Lo que culminó con la resolución A/42/169 de 2 de diciembre de 1987, de la Asamblea General de la ONU, por la que se declaró el período 1990-2000 como «EI Decenio Internacional para la Reducción de Desastres Naturales», del que España forma parte, habiéndose creado el Comité Español del Decenio para la Reducción de los Desastres Naturales de acuerdo con las recomendaciones de la ONU. Tal carácter se ha atribuido a la Comisión Nacional de Protección Civil por el RD 1301/1990 de 26 de octubre. Sobre los fines del Decenio baste señalar que consisten básicamente en:

«reducir, por medio de la acción internacionalmente concertada, especialmente en los países en vías de desarrollo, la pérdida de vidas, los daños materiales y las perturbaciones sociales y económicas cuasadas por desastres naturales como terremotos, vendavales (ciclones, huracanes, tornados, tifones) maremotos, inundaciones, desprendimientos de tierra, erupciones volcánicas, incendios y otras calamidades de origen natural como la plaga de saltamontes y langosta». 
Por una parte, desde la vertiente de la protección física de las personas y de los bienes, esto es, la de limitar las consecuencias desastrosas a que pueden dar lugar determinados riesgos, el entramadonormativo de la Protección Civil ${ }^{10}$ sigue tejiéndose a través de la aprobación de sucesivas normas ${ }^{11}$. Normas que, a la par que introducen nuevas precisiones para la planificación de las emergencias por las distintas Administraciones Públicas competentes ${ }^{12}$, están sentando las bases de una adecuada política de minimización de riesgos, que pone su énfasis tanto en la previsión como en la prevención de posibles eventos desastrosos, y utilizando certeramente a su vez frecuentes campañas de sensibilización e información ciudadana ante los principales riesgos a los que puede verse expuesta la población ${ }^{13}$.

Por otra parte, y desde una vertiente netamente ambiental, la atención prestada en los últimos años al acuciante problema del deterioro a gran escala del entorno, causado algunas veces si bien las menos por fenómenos estrictamente naturales ${ }^{14}$, ha encontrado también respuesta a nivel positivo ${ }^{15}$.

Es esa doble problemática de los riesgos naturales, y habida cuenta de las ingentes pérdidas que los mismos ocasionan ${ }^{16}$, la que reclama una adecuada política de prevención de riesgos mediante la utilización de todos los mecanismos de

${ }^{10}$ Positivamente, según el art. 1.1. de la Ley 2/1985, de 21 de enero, sobre Protección Civil, «la acción permanente de los poderes públicos, en materia de protección civil, se orientará al estudio y prevención de las situaciones de grave riesgo, catástrofe o calamidad pública y a la protección y socorro de personas y bienes en los casos en que dichas situaciones se produzcan». Sobre la problemática de la Protección Civil puede verse, entre otros, Marcos Fernando Pablo, «La Protección Civil: el marco jurídico del papel de las Comunidades Autónomas», en Revista vasca de Administración Pública no 23, 1989, pag. 47 y ss; y Miguel José Izu Belloso, «El sistema de Protección Civilenla jurisprudencia del Tribunal Constitucional», en Revista Española de Derecho Administrativo, $n^{\circ}$ 69, pag. 99 y ss.

${ }^{11}$ La más reciente e importante de las cuales es la Norma Básica de Protección Civil, aprobada por RD 407/1992, de 24 de abril, en aplicación del art. 8 de la Ley de Protección Civil.

${ }^{12}$ En el campo del reparto de competencias entre el Estado y las Comunidades Autónomas en materia de Protección Civil, y ante el silencio constitucional, hay que partir de la STC 123/1984 dictada con ocasión del conflicto positivo de competencias $n^{\circ} 568 / 1983$, promovido por el Gobierno del Estado en relación al Decreto 34/1983, de 8 de marzo, del Consejo General del País Vasco, de creación de los Centros de Coordinación Operativa; y en particular de la STC 133/1990, de 19 de julio, que resuelve conjuntamente el recurso de inconstitucionalidad y el conflicto positivo de competencias interpuestos por el Gobierno Vasco contra la Ley de Protección Civil. La anterior doctrina constitucional vendrá asumida expresamente por la Norma Básica de Protección Civil (vid. Capítulo Primero, ap. 1.2.).

${ }^{13}$ Baste señalar la famosa campaña «Todos contra el fuego» del Icona; la implantación del Teléfono Gratuito de Protección Civil, el 006 en algunas provincias; la publicación de folletos conteniendo «Recomendaciones ante el riesgo de terremoto y maremoto», «Recomendaciones ante el riesgo de tormentas y vendavales», etc.

${ }^{14}$ Por ejemplo, la desertización es en sí un riesgo natural, al igual que las inundaciones, si bien sus efectos pueden verse agravados considerablemente por la acción humana. Como ejemplo de alteración natural del ambiente debida a riesgos estrictamente naturales, y en concreto de origen volcánico, puede verse Silvia Jaquenod, «Un caso de contaminación transfronteriza de origen natural», en Cuadernos de Ordenación del Territorio, $\mathrm{n}^{\mathrm{o}} 0,1992$, pag. 3 y ss.

${ }^{15}$ Por lo que respecta a la protección del suelo, baste señalar, la Carta Europea de los Suelos, aprobada por el Consejo de Europa en 1972 o la Carta Mundial de los Suelos aprobada por la FAO en 1981.

${ }^{16}$ Para F. J. Ayala y otros, Los peligros naturales de España, publicado conjuntamente por el Instituto Tecnológico Geominero y la Dirección General de Protección Civil, Madrid, 1990, se estima que «las pérdidas por desastres naturales en España son del orden de 130.000 millones de pesetas anuales, esto es, un 0 '5\% del P.I.B.». 
prevención que pueden existir en el ordenamiento jurídico y donde, como a continuación señalaremos, la normativa de planificación territorial debe jugar un papel relevante. $Y$ ello, en fin, partiendo del convencimiento de que en el momento presente, y en el estado actual de la ciencia y la tecnología se dispone de los mecanismos adecuados para prevenir y disminuir sus efectos.

\subsection{Normas urbanísticas y prevención de riesgos naturales.}

Es necesario puntualizar que al utilizar de forma lata la expresión normas urbanísticas, con ello queremos hacer referencia al conjunto de los instrumentos de planificación previstos en la legislación vigente que de manera directa inciden sobre la ordenación del territorio.

Hecha esta precisión, antes habíamos asumido que la prevención de riesgos . naturales reclama la utilización de todo mecanismo jurídico que pueda coadyuvar a una minimización de los mismos. Parece obvio a este respecto que, incidiendo dichos riesgos las más de las veces sobre el suelo, debería ser también la normativa que disciplina la utilización del mismo, y con independencia de la legislación sectorial $^{17}$, la que integrara la planificación del territorio con la planificación de aquellos riesgos naturales que pueden afectar al mismo. Ya que te entendemos que la gestión de los riegsos naturales debe venir necesariamente asumida por la ordenación territorial, en donde la normativa urbanística, evidentemente, desempeña un papel relevante ${ }^{18}$.

Pues bien, aun siendo deseable la utilización de la normativa urbanística con funciones para la prevención de riesgos, podemos afirmar de forma categórica que ni siquiera en la más reciente legislación estatal sobre el suelo ${ }^{19}$ encontramos mención alguna a la virtualidad de la planificación urbanística en cuanto a la prevención de riesgos, en el sentido bien de la imposición de determindas medidas a los

\footnotetext{
${ }^{17}$ Como ejemplos de normas sectoriales que directa o indirectamente aspiran a la protección de los suelos, podríamos señalar: la Ley de 20 de julio sobre Conservación y mejora de suelos agrícolas; la Ley de 8 de julio de 1957, de Montes; la Ley 81/1968, de 3 de diciembre, sobre incendios forestales, o en fin, la Ley 4/1989, de 27 de marzo, de Espacios Naturales. No obstante habrá que estar principalmente a la normativa aprobada a tal fin por las Comunidades Autónomas en el ejercicio de sus competencias.

${ }^{18}$ Así, Martín Mateo, Tratado de Derecho Ambiental, Vol. II, Ed. Trivium, 1992, pag. 663, afirma que: «parecería particularmente sensato que la ocupación del suelo, especialmente para uso residencial, se realizara de acuerdo con los imperativos naturales», añadiendo además que «al menos para el futuro se debería utilizar el suelo de forma concordante con las circunstancias naturales que le afecta...». Sobre el papel de la ordenación del territorio en la gestión de los riesgos, es también ciertamente ilustrativa la opinión de Antonio Figueruelo, «Protección Civil, ordenación territorial y planeamiento urbano», en Revista de Derecho Urbanístico, no 95,1985 pag. 91 y ss., para quien no sólo esa conexión es necesaria o posible sino antes bien «la falta de ordenamiento del territorio ha introducido un nuevo factor de riesgo». Vid. asimismo, Frederick Cuny, «Desastres naturales en el desarrollo regional», Directrices ambientales para la planificación y gestión de asentamientos, del Centro de las Naciones Unidas para los asentamientos humanos, publicado en España por el M.O.P.T., Madrid, 1991.

${ }^{19}$ Nos referimos al Real Decreto Legislativo $1 / 1992$, de 26 de junio, por el que se aprueba el Texto Refundido de la Ley sobre el Régimen del Suelo y Ordenación Urbana, B.O.E. $\mathrm{n}^{\mathrm{0}} 156$ de 30 de junio.
} 
propietarios de suelo susceptible de estar afecto a riesgos naturales, bien en la prescripción de medidas directamente encaminadas a tal fin; aun cuando por lo que respecta al primer supuesto, como afirma $\mathrm{Real}^{20}$, «(si) la normativa de ordenación territorial no suele establecer directamente obligaciones positivas para los propietarios de suelo... los Planes, Programas y Proyectos derivados de la misma, se hallan lógicamente habilitados para ello».

Siendo cierto lo anterior en cuanto a la normativa general sobre el suelo, en cambio, en alguna regulación sectorial, como la de aguas, sí encontramos determinados preceptos con relevancia para la planificación territorial, y que desmuestran la relación posible entre ésta y la planificación de los riesgos ${ }^{21}$.

Es pues la generalización de esta vinculación entre la normativa urbanística a efectos de la prevención de riesgos la que se pretende. Vinculación que, si con respecto al riesgo de inundaciones existe positivamente ${ }^{22}$, nada impide que se extienda para la prevención de otros riesgos ${ }^{23}$. Ahora bien, las consecuencias que de ello se derivarían, y sin ánimo de adentrarnos en la abrumadora problemática que se cierne en torno a la gestión de los riesgos naturales, serán numerosas. No obstante, parece claro que como mínimo será necesario que la normativa de ordenación territorial tuviera presente $-\mathrm{y}$ de forma obligatoria, como requisito sine quae non para una adecuada prevención- rigurosos estudios que permitieran tanto identificar el riesgo y cuantificarlo para una zona determinada ${ }^{24}$, bien para establecer las

\footnotetext{
${ }^{20}$ Gabriel Real Ferrer, «La ordenación pública del suelo: una concepción integradora», pag. 61, inédito.

${ }^{21}$ Así en la 29/1985 de Aguas, de 2 de agosto, está previsto (art. 11.2) que «El Gobierno por decreto podrá establecer limitaciones en el uso de las zonas inundables que estime necesarias para garantizar la seguridad de las personas y los bienes», pudiendo «El Consejo de Gobierno de las Comunidades Autónomas establecer, además, normas complementarias de dicha regulación». Por «zonas inundables» hay que entender las previstas en el art. 14.3 del RD 849/1986, de 11 de abril, por el que se aprueba el Reglamento de Dominio Público Hidráulico. Por su parte, el art. 401 ) de la Ley de Aguas dispone que los Planes Hidrológicos de cuenca comprenderán «los criterios sobre estudios, actuaciones y obras para prevenir y evitar los daños debidos a inundaciones, avenidas y otros fenómenos hidráulicos».

${ }^{22}$ Lo que deriva en primer lugar del hecho de que los Planes Hidrológicos son «públicos y vinculantes» (art. 38.3 Ley de Aguas), y en segundo lugar, del hecho de que los mismos deben elaborarse «en coordinación con las diferentes planificaciones que les afecten» (art. 38. 4 Ley de Aguas). De forma inequívoca además, el art. 120.1 del Reglamento de la Adminmistración Pública del Agua y de la Planificación Hidrológica, contiene una mención expresa de determinadas previsiones de los Planes Hidrológicos, las de los arts. 41.4 y 2 de la Ley de Aguas, que «deberán ser respetadas en los diferentes intrumentos de ordenación urbanística del territorio».

Por su parte, en el Proyecto de Directrices del Plan Hidrológico del Segura se pretende prohibir la edificación en zonas situadas junto a los cauces en los que existan probabilidades de que se produzca una riada en el plazo de 50 o 100 años, sergún el diario «Información», del 10 de junio de 1992.

${ }^{23} \mathrm{E} 1$ legislador autonómico parece seguir apostando por esa vía. Así, en el Borrador del Anteproyecto de Ley Forestal de la Comunidad Valenciana, se dispone en su art. 6.2. que: «los instrumentos de ordenación del territorio..., deberán incorporar los medios necesarios para facilitar la conservación y la expansión de los terrenos forestales». «Conservación», que evidentemente deberá serlo a todos los efectos, incuyendo la prevención frente a los riesgos que puedan afectar a dichos terrenos.

${ }^{24}$ En este sentido existen para el territorio de la Comunidad Autónoma de Valencia estudios, de ámbito provincial, en los que se recoge de forma sumamente detallada los riesgos que afectan a nuestro territorio, y que deberían servir como punto de arranque para integrar la planificación de riesgos en la
} 
limitaciones necesarias al uso de los suelos, bien para arbitrar las medidas oportunas de obligado cumplimmiento por los propietarios de dichos suelos, al objeto de la reducción de los riesgos identificados ${ }^{25}$.

Es precisamente ese doble cambio cualitativo, por una parte la de una norma urbanística como instrumento para la prevención de riesgos naturales, y por otra la determinación de medidas de obligado cumplimiento por los propietarios de suelo a dicho fin, el que se produce en la Ley valenciana de Suelo no Urbanizable como seguidamente señalaremos.

\section{Incidencias de la Ley de suelo no urbanizable para la actuación frente a riesgos naturales}

Como habíamos apuntado al inicio de esta reflexión la Ley autonómica introduce determinados supuestos puntuales que directamente tienen una incidencia en materia de prevención de posibles riesgos, y que vienen a proyectar prácticamente su campo de aplicación, y habida cuenta del ámbito material de la Ley, sobre los deberes que a tal efecto deben cumplir los propietarios de suelo no urbanizable, tanto común, como sujeto a epecial protección ${ }^{26}$.

Las previsiones legales, entre las que se encuentran aspectos ciertamente novedosos, las podemos dividir a efectos puramente sistemáticos en:

a) Medidas dirigidas a la Administración planificadora.

«No se podrá clasificar o reclasificar, como urbano, urbanizable o apto para la urbanización, suelo no urbanizable que haya sufrido los efectos de un incendio forestal ${ }^{27} . »$

Esta previsión legal apunta claramente a la protección del suelo frente a uno de los problemas básicos de nuestra Comunidad como es el de los incendios forestales ${ }^{28}$, pretendiendo con ello el legislador excluir del tráfico urbanístico aquellos

ordenación territorial. Vid. art. 7, Ley 6/1989, 7 de julio, de ordenación del Territorio de la Comunidad Valenciana.

${ }^{25}$ En este aspecto es sumamente interesante la experiencia francesa, que arranca plenamente con la Ley $\mathrm{n}^{\mathrm{9}} 87-565$, de 22 de julio de 1987 relativa a la «organización de la seguridad divil, a la protección del bosque contra incendios y a la prevención de riesgos mayores», por mor de la cual a los llamados Planes de Ocupación del Suelo (similares a nuestros Planes Generales de Ordenación Urbana) se les anexa un Plan de Exposición a Riesgos, en el cual se determinan las zonas vulnerables a un riesgo determinado, introduciendo prescripciones de obligado cumplimiento tanto para las autoridades públicas planificadoras, como para los particulares afectados. Vid. al respecto, «Les études préliminaires à la cartographie réglamentaire des risques naturales majeurs», La Documentation Française, París 1990; por lo que atañe al riesgo de inundación, vid. «La cartographie des Plans d'Expositions au Risque Inundation», La Documentation Française, París, 1988.

${ }^{26}$ Vid. nota 4.

${ }^{27}$ Art. 2.4.

${ }^{28}$ Desgraciadamente conocido y destacado por todos. Vid. al respecto el Libro Blanco sobre los incendios forestales, publicado por la Generalitat Valenciana, Valencia 1986. También, Santiago Reyna Domenech, «Los incendios forestales en la Comunidad Valenciana. Riesgo, evolución y líneas de actuación», en Revista Valenciana d'Estudis Autonòmics, nº 7, 1987, pag. 259 y ss. 
terrenos que hayan sufrido los efectos de un incendio foresta ${ }^{29}$, pues no es infrecuente que detrás de las causas intencionadas de algunos incendios forestales, se escondan intereses urbanísticos oscuros ${ }^{30}$.

b) Medidas dirigidas a los propietarios de suelo no urbanizable.

Estas a su vez se pueden dividir en:

1. Obligaciones positivas de hacer:

- «Consevar y mantener el suelo y su masa vegetal en las condiciones precisas para evitar riesgos de erosión, incendio o para la seguridad o salud públicas o cualquier otra perturbación medioambiental, así como daños o perjuicios a terceros o al interés general y efectuar las labores de replantación y, en su caso, reforestación precisas para la reposición de la vegetación en toda la superficie de los terrenos que la hayan perdido como consecuencia de incendio, desastre natural o acción humana no debidamente autorizada, dentro de los plazos señalados en los planes y programas sectoriales reguladores de la materia ${ }^{31} . »$

- «Realizar las plantaciones y los trabajos y obras de defensa del suelo y su vegetación que sean necesarios para salvaguardar el equilibrio ecológico, preservar el suelo de la erosión, impedir la contaminación del mismo y prevenir desastres naturales ${ }^{32}$.»

2. Obligaciones negativas y de soportar.

- «Abstenerse de realizar cualesquiera actividades o actos que puedan tener como consecuencia o efecto la contaminación de la tierra, el agua o el aire ${ }^{33}$.»

- «Permitir, en los terrenos de su propiedad en los que, por sus características, así sea preciso, la ejecución por los órganos competentes de la Generalidad de trabajos de plantación destinados a prevenir la erosión... ${ }^{34}$.»

\footnotetext{
${ }^{29}$ Exclusión qu se mantiene en el art. 73.2. del Borrador del Anteproyecto de Ley Forestal de la Comunidad Valenciana.

${ }^{30}$ Vid. Antonio Vercher Noguera, «Ministerio Fiscal, incendios forestales y perspectivas de colaboración», en Revista de Derecho Ambiental, $n^{\circ}$ 8, 1992, pag. 45, el cual afirma que «...existen indicios en el sentido de que algunas transformaciones agrícolas o inversiones inmobiliarias en terrenos afectados por incendios forestales han utilizado activo monetario procedente de fraude fiscal.»

${ }^{31} \mathrm{Art}$. 5. B) $2^{\circ}$. No obstante, para paliar esta gravosa obligación que pesa sobre el propietario, la Ley prevé que «cuando el coste de la replantación o reforestación... exceda de la mitad del valor de la finca en su conjunto, determinado conforme a la legislación urbanística, el propietario podrá solicitar, y la Generalidad otorgarle, ayudas, que podrán ser incluso a fondo perdido por lo que hace al exceso...» (art. 5. B) $7^{\circ}$ tercer párrafo). En caso contrario, «también podrán otorgarsde ayudas para obras que no alcancen el valor indicado y cuya ejecución sea obligación del propietario, siempre que éste se encuentre en una situación socioeconómica merecedora de especial protección o cuando efectúen una cesión de terrenos al patrimonio de la Administración equivalente a la ayuda percibida» (art. 5. B) $7^{\circ}$ tercer párrafo.

${ }^{32}$ Art. 5. B) $3^{\circ}$.

${ }^{33}$ Art. 5. B) $4^{\circ}$. Vid. la precisión al respecto en nota 7.

${ }^{34}$ Art. 5. B) $7^{\circ}$
} 
Señalar por último que en caso de «incumplimiento manifiesto» de estos deberes por el propietario, la Administracion puede expropiar los terrenos correspondientes ${ }^{35}$.

\section{Conclusiones}

La articulación de una política adecuada para la prevención de los efectos catastróficos de aquellos riesgos naturales que puede soportar una determinada comunidad, unida a los problemas, que desde una perspectiva puramente ambiental pueden afectar a la misma, obliga a revisar los mecanismos típicos de prevención de dichos riesgos, una vez superada ya la etapa de respuestas ad hoc para hacer frente a la catástrofe. En este sentido, es necesario extender también la filosofía de la prevención a aquellos sectores del ordenamiento jurídico, como pueda ser el urbanístico y, por encima de éste, al de la ordenación territorial, a fin de integrar la planificación de dichos riesgos en aquella que ordena el marco natural en donde los mismos se manifiestan: el territorio. Y ello a fin de utilizar todas las posibilidades que el ordenamiento jurídico ofrece al respecto, esfuerzo este - de serlo- justificado por los cuantiosos daños que dichos riesgos ocasionan.

La singularidad de la Ley valenciana de suelo no urbanizable en este sentido, deriva precisamente de esa conexión que se establece entre una norma urbanística como posible instrumento para la prevención de riesgos. Habiendo sido acreditada la importancia de aquélla, la Ley valenciana demuestra con ello la naturalidad de dicha conexión, a través de las medidas previstas en la norma. Cuestión distinta será, ciertamente, la incidencia que las mismas tengan en cuanto a la protección del maltrecho territorio de nuestra Comunidad, así como el celo con que los responsables públicos valencianos las apliquen.

${ }^{35}$ Art. 5. B) $7^{\circ}$ in fine. 